\title{
FUNCTIONALIZATION OF MULTI-WALLED CARBON NANOTUBES AND ITS IMPACT ON GROWTH OF TOMATO PLANT (Solanum lycopersicum L.)
}

\author{
Kalpana Awasthi ${ }^{1}$, Dheerj Kumar Tripathi ${ }^{2}$, Rajani Srivastava ${ }^{2 *}$ \\ ${ }^{1}$ Department of Physics, K.N. Govt. P.G. College, Gyanpur, Bhadohi-221304, India \\ ${ }^{2}$ Environmental Science (Environmental Technology), Institute of Environment \& Sustainable Development, RGSC, Banaras Hindu University, Mirzapur, 231001, India \\ Received - May 11, 2020; Revision - June 20, 2020; Accepted - August 16, 2020 \\ Available Online - August 25, 2020
}

DOI: http://dx.doi.org/10.18006/2020.8(4).469.478

\section{KEYWORDS \\ Carbon nanotubes \\ Functionalization \\ Plant growth \\ Productivity \\ Tomato plant \\ Soil}

\begin{abstract}
The uptake of carbon nanotubes (CNTs) by plants has shown a recent field of nano-agriculture. The potential effects of synthesized CNTs and carboxylic group functionalized CNTs (FCNTs) on the growth of tomato plants were evaluated by examining their effects on plant height, the number of leaves, and fruits. The CNTs have been synthesized by spray pyrolysis assisted chemical vapor deposition method. The carboxylic group FCNTs has been prepared by chemical oxidation method. The scanning, transmission electron microscopy, and fourier transformed infrared spectroscopy techniques were used to characterize the CNTs/ FCNTs samples. The characterization shows that the prepared CNTs are multi-walled CNTs. The as-grown CNTs are well graphitized and the presence of functional group is confirmed by fourier transformed infrared spectroscopy. Tomato plants grown in soil supplemented with FCNTs were produced two times flowers and fruit compared to plants grown in control soil.
\end{abstract}

* Corresponding author

E-mail: srivastava_252003@yahoo.com; rajani.srivastava25@gmail.com (Rajani Srivastava)

Peer review under responsibility of Journal of Experimental Biology and Agricultural Sciences.

Production and Hosting by Horizon Publisher India [HPI] (http://www.horizonpublisherindia.in/).

All rights reserved.
All the articles published by Journal of Experimental Biology and Agricultural Sciences are licensed under a Creative Commons Attribution-NonCommercial 4.0 International License Based on a work at www.jebas.org.

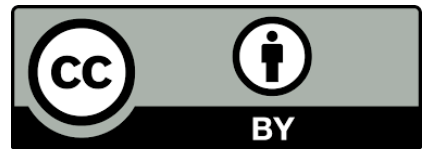




\section{Introduction}

The field of nanotechnology has gained attention in the current decade due to its unique properties and diverse applications in different fields of science and technology such as electronics, medicine, solar, pharmaceuticals and agriculture (Khot et al., 2012; Parisi et al., 2015; Manjunatha et al., 2016; Srivastava et al., 2018; Chhipa, 2019). Various metal, metal oxide, polymer based nano-materials, carbon nano-materials, engineered nanomaterials and nano-formulations with active ingredient based nano-fertilizers and nano-pesticides showed their potential role in sustainable agriculture production (Prasad et al., 2014; Abbas et al., 2016; Mukherjee et al., 2016; Srivastava, 2019). The aim of using nanomaterials in agriculture is to reduce the amount of sprayed chemical products by smart delivery of active ingredients, minimize nutrient losses in fertilization and increase yields through optimized water and nutrient management. Different types of carbon nanomaterials including fullerene, graphene, nano fibers, carbon nanotubes (CNTs) and quantum dots have been widely used for numerous applications in different fields of agricultural and plant science (Mukherjee et al., 2016; Mohamed et al., 2018; Verma et al., 2019; Awasthi \& Awasthi, 2019). Among them, CNTs have an important role in direct delivery systems for pesticides and fertilizer (Patel et al., 2019). It is demonstrated that CNTs can traverse across both the plant cell wall and cell membrane (Khodakovskaya et al., 2009). The higher seed germination rate was reported in crop species such as tomato (Srinivasan \& Saraswathi, 2010), Indian mustard (Brassica juncea) (Ghodake et al., 2010), urd bean (Vigna mungo), rice (Oryza sativa), soybean, corn (Zea mays), barley(Hordeum vulgare), castor (Ricinus communis L.) and hybrid Bt cotton (Gossypium hirsutum) with CNTs treatment (Nalwade \& Neharkar, 2013; Lahiani et al., 2013). Several works have been carried out on the plant growth enhancement using oxidized CNTs exposure. The effect of pristine and oxidized CNTs on the growth of mustard (B. juncea) reported by Mondal et al. (2011). The higher rates of seed germination, increased root and shoot growth were observed at the lower concentration of oxidized CNTs. Oxidized CNTs at the lowest concentration (2.3$46.0 \mathrm{mg} / \mathrm{L}$ ) yielded higher rates of seed germination $\sim 99 \%$ than the pristine CNTs $\sim 94 \%$. At the higher CNTs exposure, the seed germination rate is decreased. In another study, Wang et al. (2012) reported the $\sim 50 \%$ and $32 \%$ increase in root length of wheat seedling under exposure of $40-160 \mathrm{mg} / \mathrm{L}$ oxidized CNTs, respectively.

Due to high surface energy CNTs tend to aggregate together and it is difficult to disperse in aqueous media. So, the poor dispersion/ solubility of CNTs have hindered their use in the biological and biomedical field. To overcome this problem, the modification of the surface of CNT i.e. functionalization has received much attention. Under this process, the different molecule is introduced onto the surface of CNTs by adsorption, electrostatic interaction or covalent bonding. Through such modifications, the water solubility of CNT is improved and bundling /aggregation of nanotubes is also reduced. Therefore, the functionalized CNTs have made it possible to solubilize and disperse CNTs in water and opening the path for their facile manipulation and processing in physiological environments. The impact of citrate coated water-soluble CNTs in gram (Cicer arietinum) seed growth was studied and visualized internalization of the CNTs by electron microscopy (Tripathi et al., 2011). It is suggested that the formation of an aligned network of CNTs increased the water uptake efficiency and resulted in plant growth. The water-soluble CNTs also increased the growth rate in every part of the plant including the roots, shoots and also in branching. The effects of functionalized carbon nanotubes (FCNTs) and pristine CNTs on root elongation of different crop species, cabbage (Brassica oleracea), carrot (Daucus carota), cucumber (Cucumis sativus), lettuce (Lactuca sativa) and onion (Allium cepa) were reported (Srivastava \& Rao, 2014). It has been reported that CNTs at relatively low doses $(10-40 \mu \mathrm{g} / \mathrm{mL})$ can penetrate thick seed coats and enhanced the growth of tomato plants (Khodakovskaya et al., 2009). In another study, the effects of CNTs delivered during watering on the phenotype of mature tomato plants were studied (Khodakovaskaya et al., 2013). It was reported that the soil mixture increased the flowers and fruits as compared to the plants that were unexposed to CNTs. In the present study, FCNTs were prepared by the chemical oxidation method. The prepared CNTs and FCNTs were studied by scanning electron microscopy, transmission electron microscopy and fourier transformed infrared spectroscopy. Various previous works showed the application of CNT or FCNT on root elongation, shoot growth, fruit and flower number separately. Effect of carbon nanotubes on soil physico-chemical properties and overall biological productivity is lacking. So, this study aims to prepare CNT and functionalize it. Then, see the effect of the application of CNT and FCNT on soil properties and crop productivity (Solanum lycopersicum).

\section{Materials and Methods}

\subsection{Study Site}

The present work was carried out at Farmer's hostel in Rajiv Gandhi South Campus, BHU, Barkachha, district Mirzapur, Uttar Pradesh $\left(25^{\circ} 10^{\prime}\right.$ latitude, $82^{\circ} 37^{\prime}$ longitude and altitude of 427 meters above mean sea level), India. This area is one of the seven most drought-prone districts of Uttar Pradesh. Semi-arid type of climate prevails here with an average $1100 \mathrm{~mm}$ annual precipitation. Approximately $90 \%$ of rain received during the monsoon. The major portion of the study area is rocky, underground water resources are limited and untapped to take advantage of potential agriculture production. Mirzapur falls in a belt of semi-arid to sub-humid climate. 
Table 1 Initial mechanical and physico-chemical characteristics of experimental soil

\begin{tabular}{|c|c|}
\hline Particulars and Method & Observations \\
\hline \multicolumn{2}{|l|}{ Mechanical analysis } \\
\hline Sand (\%) & $55.25 \pm 2.5$ \\
\hline Silt (\%) & $30.45 \pm 1.8$ \\
\hline Clay (\%) & $14.30 \pm 0.6$ \\
\hline Textural class & Sandy loam \\
\hline \multicolumn{2}{|c|}{ Physical analysis } \\
\hline $\begin{array}{l}\text { Bulk density }\left(\mathrm{g} / \mathrm{cm}^{3}\right) \\
\text { Core method (dry weight/volume) }\end{array}$ & $1.59 \pm 0.006$ \\
\hline $\begin{array}{l}\text { Soil moisture }(\%) \\
\text { Dry mass basis }\end{array}$ & $8.57 \pm 0.01$ \\
\hline $\begin{array}{l}\text { Water holding capacity (\%) } \\
\text { Perforated brass box (Piper, 1966) }\end{array}$ & $28.4 \pm 0.05$ \\
\hline \multicolumn{2}{|c|}{ Chemical analysis } \\
\hline $\begin{array}{l}\text { Organic carbon (\%) } \\
\text { Wet digestion (Walkley,1947) }\end{array}$ & $0.48 \pm 0.007$ \\
\hline $\begin{array}{l}\text { Total N (\%) } \\
\quad \text { Modified Kjeldhal method (Jackson, 1958) }\end{array}$ & $0.045 \pm 0.006$ \\
\hline $\mathrm{pH} \quad(1: 2.5$ soil water suspension $)$ & $7.1 \pm 0.0002$ \\
\hline
\end{tabular}

Values are replicate (nine) mean \pm SE.

\subsection{Soil}

The soil of this region is sandy loam red laterite in texture. The soil is slightly acidic in reaction $(6-5 \mathrm{pH})$, poor in nitrogen as well as phosphorus and moderate in potash. The soil has a poor amount of organic carbon below $0.5 \%$ (Srivastava et al., 2020). Therefore, the vegetation is scared in this region due to poor nutrient availability in soil and extreme dry climatic conditions. The experiment was carried out in Farmer's Hostel field during the year 2017. The experiment was designed with the incorporation of multi-walled CNTs and test crop-tomato (S. lycopersicum). About $150 \mathrm{~kg}$ of soil was prepared by excavating the upper layer of soil. The blocks of soil were broken down into smaller particles and then sieving of soil was done. Mixing of soil and farmyard manure was done in the ratio 3:1. The prepared, homogenize soil was filled in the pots (each pot was $24.5 \mathrm{~cm}$ in diameter and $19 \mathrm{~cm}$ height). About $5 \mathrm{~kg}$ of soil was filled in each pot.

\subsection{Seedlings preparation and transplant}

The seedlings of tomato were purchased from Vegetable Research Institute, Varanasi. The seedlings were washed under the running tap water and then were dipped into CNTs (functionalized and non-functionalized) solution overnight at room temperature. Later, seedlings were transplanted in different pots containing functionalized and non-functionalized CNTs. The control (without CNTs and FCNTs treated) tomato plants were also planted into prepared soil about two inches deep. Three seedlings were transplanted in each pot at equal distance. Before transplanting the seedlings, a soil sample was drawn to determine the initial mechanical, physical and chemical parameters of soil. Vegetation analysis (including measurement of plant height, number of leaves, number of buds etc.) was done at 15 days interval. Soil samples were also collected from each treatment pots and control pots for physical and chemical analysis after tomato plant harvest. The initial and final soil parameters that were analyzed are soil moisture, bulk density, water holding capacity and $\mathrm{pH}$, organic carbon and total nitrogen of soil. Various methods for analyzing different parameters of soil are mentioned in Table 1. All pots were placed in an experimental plot that was covered with nylon net at top and sides to prevent litter blown from external sources or the bird herbivory.

\subsection{Preparation of CNTs and FCNTs and their characterizations}

The CNTs were synthesized by the spray pyrolysis of ferrocene and benzene solution at $850^{\circ} \mathrm{C}$ in an argon atmosphere (Srivastava et al., 2004). The concentration of ferrocene in benzene was $50 \mathrm{mg} / \mathrm{ml}$ and the flow rate of the precursor solution was found to be $\sim 2 \mathrm{ml} / \mathrm{min}$. To remove the metal particles (iron), as grown 
CNTs soot was treated with diluted $\mathrm{HNO}_{3}$ for 24 hours at room temperature and washed with distilled water. The purified CNTs were dried at $100^{\circ} \mathrm{C}$ in the air for five hours (Figure 1). The carboxylic group functionalized CNTs were prepared by chemical oxidation method. The as-synthesized CNTs $(0.5 \mathrm{mg})$ were dispersed in a mixture of concentrate $\mathrm{H}_{2} \mathrm{SO}_{4}$ and concentrate $\mathrm{HNO}_{3}$ (3:1 vol.) and sonicated for two hours at room temperature. The suspension was refluxed under magnetic stirring at room temperature for eight hours. The resulting suspension was washed with distilled water and dried at $80^{\circ} \mathrm{C}$ for 30 minutes. The microstructures of as prepared CNTs and FCNTs were investigated by scanning electron microscopy (SEM) (FEI:Quanta 200) and transmission electron microscopy (TEM) (Technai $20 \mathrm{G}^{2}$ ) equipped with energy dispersive X-ray spectrometer (EDS). Functionalization of CNTs was examined by Fourier transform infrared (FTIR) [Perkin-Elmer (Spectrum 100, USA)] spectroscopy. The synthesis and characterization of CNTs/ FCNTs were done at Nano science laboratory, Department of physics, Institute of Science, Banaras Hindu University, Varanasi. The functionalization process of CNTs was carried out at K. N. Govt. P.G. College, Gyanpur.

\subsection{Statistical analysis}

Statistical analysis of data was done using the SPSS package (version 16, USA). Values are expressed as mean \pm standard error. Mean values are compared by using the least significant difference (LSD) range test procedure at the $5 \%$ level of significance.

\section{Results and Discussion}

The prepared CNTs and FCNTs $(1 \mathrm{mg})$ were added in $10 \mathrm{ml}$ of distilled water and sonicated in an ultrasonic bath at room temperature for two hours. Figure 1 shows the optical photographs of the CNTs/ FCNTs dispersion in distilled water. As can be seen from this figure, synthesized CNTs are insoluble in water while the FCNTs are homogeneously dispersed in distilled water. This was also confirmed by Janas \& Stando (2017). The stability of the water dispersion of the FCNTs was examined for one day and no precipitation was detected. However, the pristine CNTs were settled down after two hours. The presence of hydrophilic functional groups onto the CNTs i.e. carboxyl, hydroxyl or sulfonate groups increased the water solubility of CNTs (Kharisov et al., 2009).

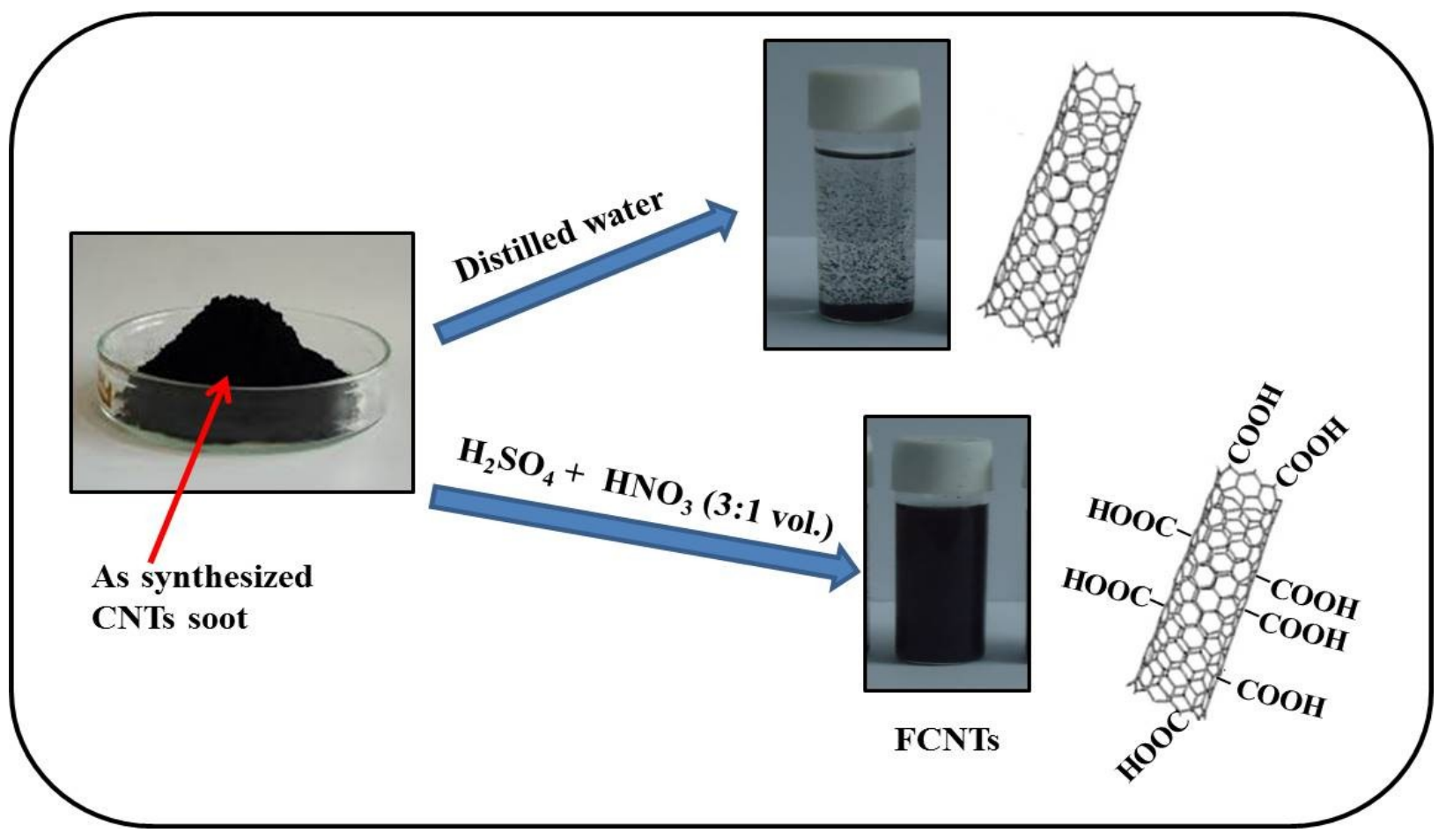

Figure 1 Schematic representation of the formation of FCNTs (functionalized multi-walled carbon nanotubes) and dispersion of CNTs (Multi-walled carbon nanotubes) and FCNTs in distilled water 

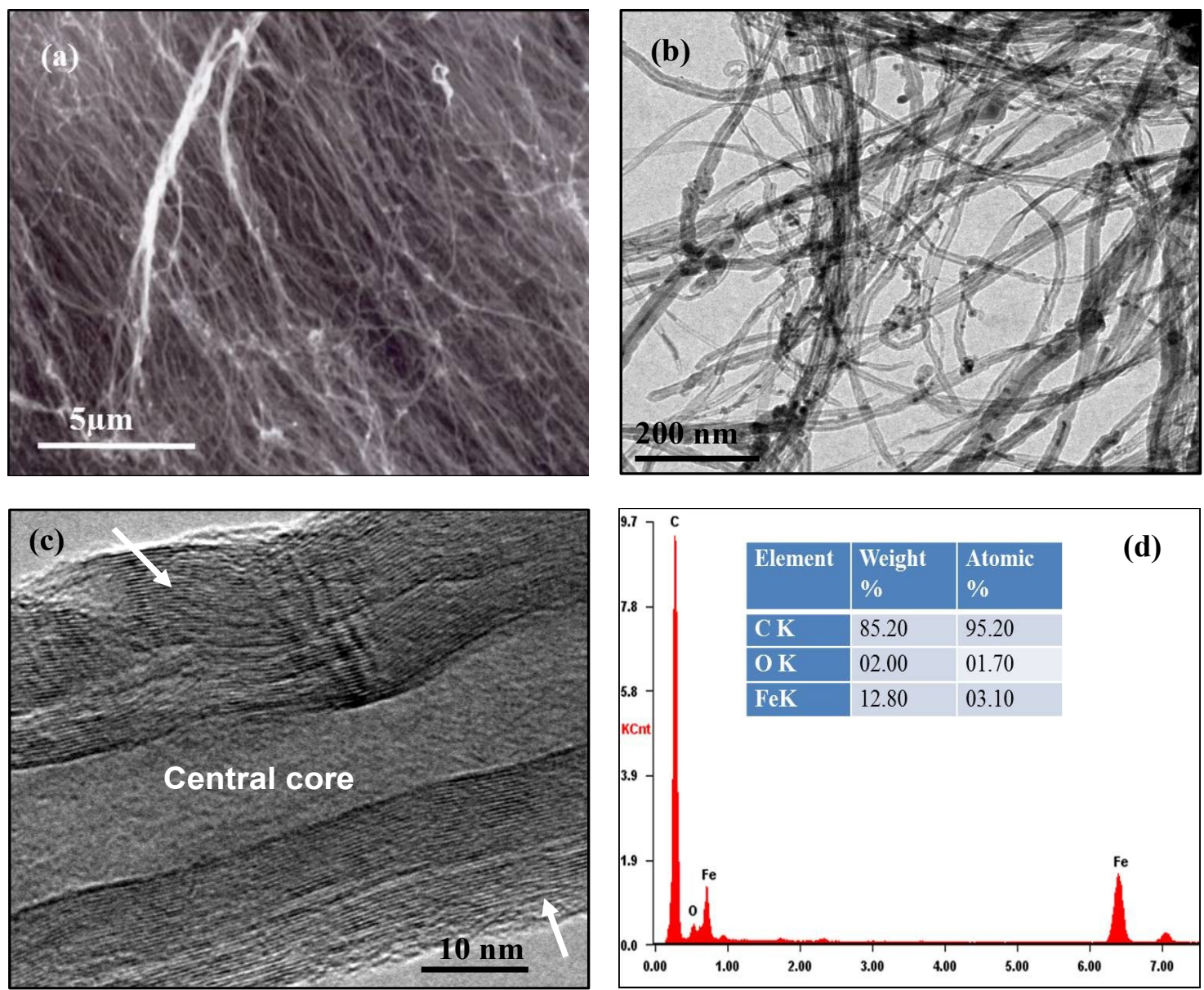

Figure 2 (a) SEM and (b) TEM micrographs of as synthesized CNTs. (c) High resolution TEM image of CNT. Arrow shows the layers of MWCNT. (d) Energy dispersive spectrum of as-synthesized CNTs

\subsection{Microstructural characterization of synthesized CNTs}

The SEM and TEM images of as-synthesized CNTs are shown in Figure 2(a) to (c). Figure 2(a) shows the formation of CNTs in a bundle. The length of CNTs varies from $\sim 5-15 \mu \mathrm{m}$. Some white particles i.e. iron $(\mathrm{Fe})$ catalyst particles are also observed with CNTs. The Fe catalyst is coming from the dissociation of ferrocene, which was used as a catalyst to synthesize CNTs. The microstructure of the as grown CNTs was investigated by TEM. Figure 2(b) exhibits the TEM image of as synthesized CNTs. As can be seen, the as synthesized CNTs are clean and free from other carbonaceous materials. The diameter of CNTs is $\sim 30-50 \mathrm{~nm}$. Some of CNTs are partially filled with iron catalyst. The layers of multi walled CNT can be seen in high resolution TEM image (Figure 2-c). This image reveals the well-graphitized multi walled CNT layers (marked by arrows) and empty central core. The representative energy dispersive spectrum of as synthesized CNTs is shown in Figure 2(d). The $\mathrm{C}$ and Fe peaks observed in the spectra are present from CNTs and catalyst employed for the formation of CNTs, respectively. The Fe content is found to be $\sim 12.8 \mathrm{wt} \%$. The oxygen $(\mathrm{O})$ is present from water which is used for TEM sample preparation. The spray pyrolysis method is a low temperature synthesis route to grow crystalline CNTs in high yield. It is suggested that the benzene- ferrocene solution flow with the $\mathrm{Ar}$ gas into the hot zone of quartz tube and Fe particles are deposited on the inner walls of the tube. A further supply of precursor solution allows dissociation of hydrocarbon on these precipitated $\mathrm{Fe}$ particles and CNTs grow on the Fe particles forming the cylindrical configuration (Srivastava et al., 2004). The image of FCNTs is shown in Figure 3. The surface of FCNTs is rough due to the treatment of CNTs with strong oxidizing agent.

\subsection{FTIR Analysis of CNTs and FCNTs}

The presence of functional groups onto the surface of CNTs after functionalization was examined by FTIR spectroscopy. The FTIR 


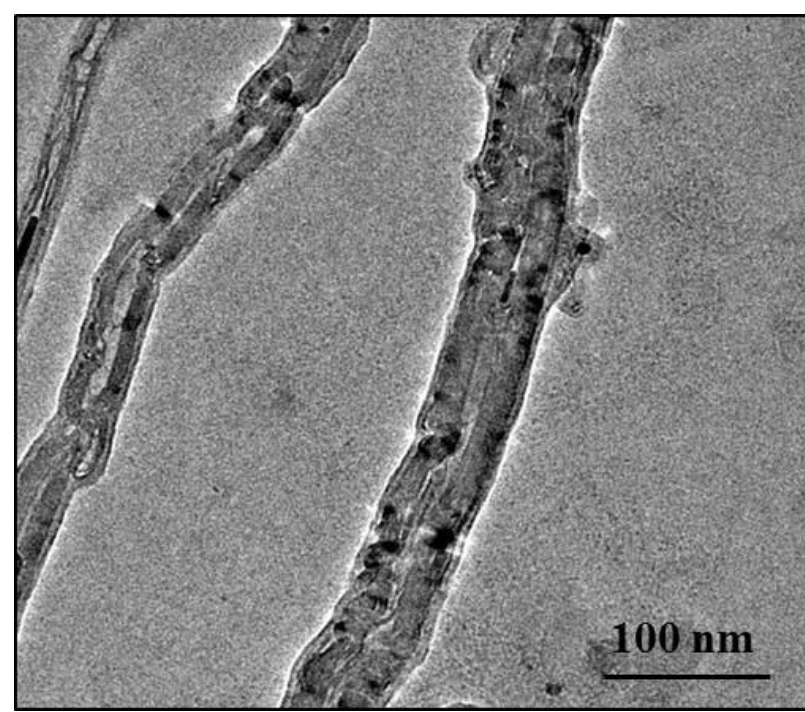

Figure 3 TEM micrograph of CNTs (Multi-walled carbon nanotubes) after functionalization

spectrum of as synthesized CNTs is shown in Figure 4(a). The peak at $3440 \mathrm{~cm}^{-1}$ corresponds to the presence of $\mathrm{OH}$ groups on the surface of CNTs and is present due to the ambient atmospheric moisture. The peak at $1600 \mathrm{~cm}^{-1}$ is attributed to the $\mathrm{C}=\mathrm{C}$ stretching vibration of CNTs. In the FTIR spectra of FCNTs (Figure $4 \mathrm{~b}$ ), the peak at $1710 \mathrm{~cm}^{-1}$ is associated to the $\mathrm{C}=\mathrm{O}$ stretching of the carboxylic (COOH) group (Stobinski et al., 2010). The peaks at $1365 \mathrm{~cm}^{-1}$ and $1172 \mathrm{~cm}^{-1}$ represent the $\mathrm{O}-\mathrm{H}$ and $\mathrm{C}-\mathrm{O}$ stretching vibrations of carboxylic group. This observation confirms the presence of $-\mathrm{COOH}$ groups on to the surface of CNTs. The solubility of CNTs in water and the organic solvent was increased in the presence of hydrophilic functional groups to CNTs such as carboxyl, hydroxyl or sulfonate groups. The carboxylic groups attached to the nanotube surface can serve as sites for further functionalization. Janas \& Stando (2017) also discussed the method of functionalization.

\subsection{Effect of CNTs and FCNTs on the growth of tomato plants and soil}

Before transplanting tomato seedlings, initial soil samples were taken to determine the physical and chemical quality of the soil. The initial mechanical and physico-chemical analysis of experimental soil is listed in Table 1. The values of soil moisture, water holding capacity, organic carbon and total nitrogen of soil were reported lower in the initial soil sample. The soil is sandy loam in texture. Vegetation was scarce in the experimental area; it was classified as semiarid to sub-humid climatic area. The changes in physicochemical properties of soil after the treatment of CNTs and FCNTs experiments were estimated (Table 2). It is observed that there were increases in the soil moisture and this was maximum in FCNTs treatment $(18 \%)$ and it was followed by CNTs $(10 \%)$ in comparison to control (8\%). In comparison to control, water

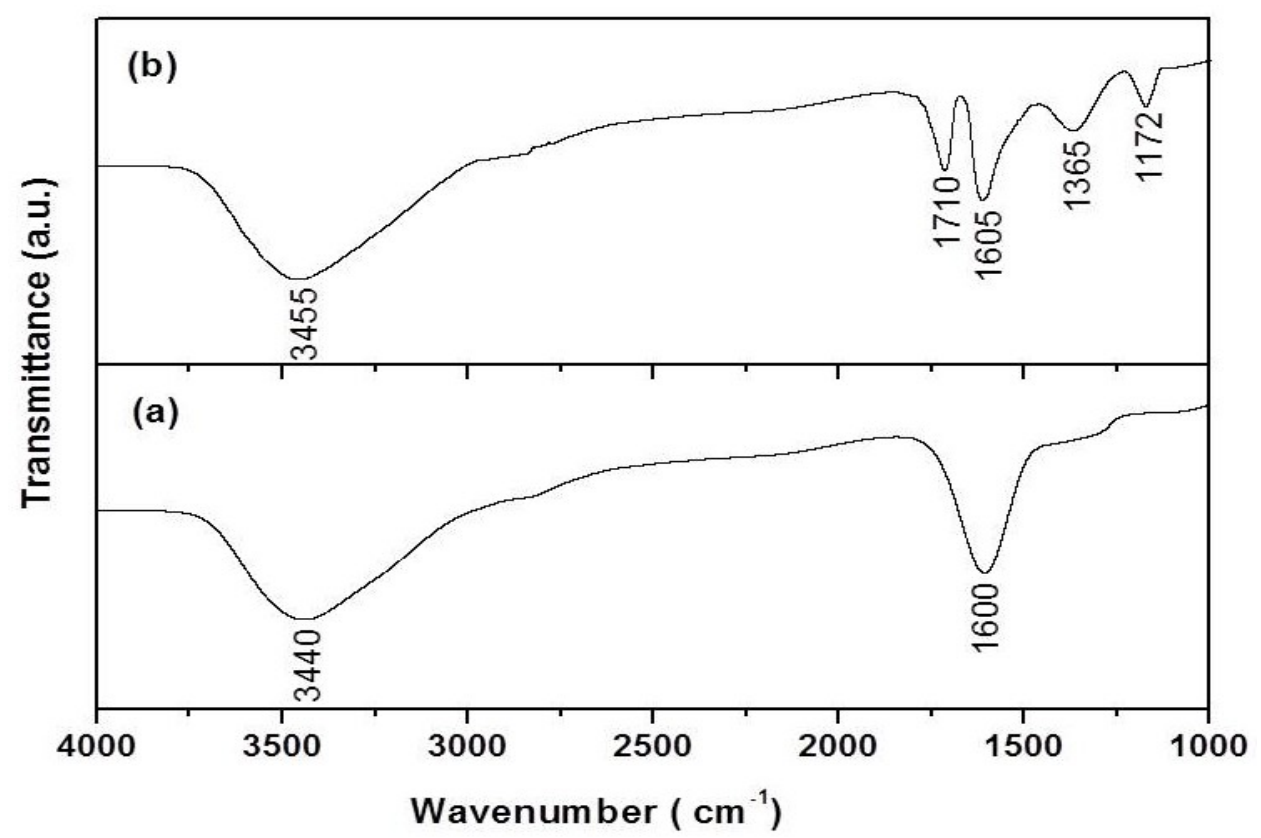

Figure 4 FTIR spectra of as synthesized CNTs (a) and after functionalization (b) 
Table 2 Variations in physico-chemical characteristics of soil after harvest of tomato plants

\begin{tabular}{|lccc|}
\hline \multicolumn{1}{|l}{ Particulars } & Treatments & FCNTs \\
\hline Soil moisture (\%) & Control & CNTs & $18.0 \pm 0.47$ \\
\hline Water holding capacity (\%) & $8.07 \pm 0.24$ & $10.33 \pm 0.27$ & $49.70 \pm 0.005$ \\
\hline \multicolumn{2}{|c|}{ Chemical analysis } & $36.04 \pm 0.009$ & $0.96 \pm 0.01$ \\
\hline Organic Carbon (\%) & $28.53 \pm 0.009$ & $0.76 \pm 0.009$ & $0.15 \pm 0.01$ \\
\hline Total N $(\%)$ & $0.48 \pm 0.007$ & $0.075 \pm 0.001$ & $6.8 \pm 0.04$ \\
\hline $\mathrm{pH}$ & $0.048 \pm 0.001$ & $6.8 \pm 0.05$ & \\
\hline Values are replicate mean \pm SE and are significant at $0.05(p<0.05)$. & & \\
\hline
\end{tabular}

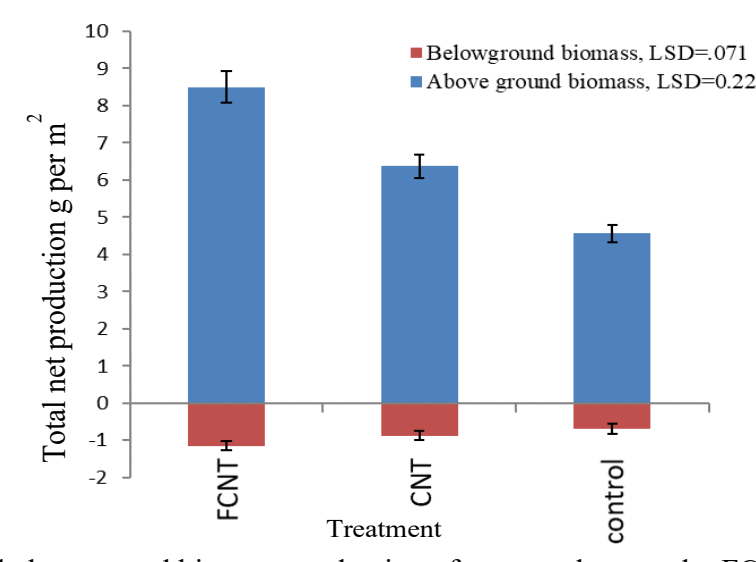

Figure 5 Above ground and below ground biomass production of tomato plants under FCNT (functionalized multi-walled carbon nanotubes) and CNT (multi-walled carbon nanotubes) treatments. The values are represented as mean $\pm \mathrm{SE}$

(standard error) of triplicate samples and significant at $0.05(\mathrm{p}<0.05)$

holding capacity was $26 \%$ higher in CNTs and $74 \%$ in FCNTs treatment. Husen \& Siddiqi (2014) worked on functionalized and non-functionalized carbon nanomaterials and observed their effect on soil quality and plant growth. According to them, CNTs influence fruit and crop production in edible plants and vegetables. The fullerene $\left(\mathrm{C}_{60}\right)$ and $\mathrm{CNTs}$ have been shown to increase the water-retaining capacity, biomass and fruit yield in plants up to $\sim 118 \%$. The application of a very small amount of carbon nanotubes $\left(50 \mu \mathrm{g} \mathrm{mL}^{-1}\right)$ increases tomato production by about $200 \%$.

The carbon and nitrogen content in soil was also increased after the treatment with CNTs and FCNTs (Table 2). The FCNTs treated soil showed the highest value of organic carbon content $(0.96 \%)$ which is about two times higher than the control $(0.48 \%)$, facilitating the accumulation of a large amount of organic matter promoting the significant growth of the plant. Whereas, in CNTs treated soil showed one and half time increase in organic carbon. The values of total nitrogen content in soil was also found maximum in FCNTs treatment $(0.15 \%)$ followed by CNTs $(0.075 \%)$ as a comparison to control. Nitrogen content is thus available for absorption by plants and enhances plant growth treatment's wise. Patel et al. (2019), summarizes various studies and concluded that exposure of CNTs at higher expanse amplified the phytohormones level in rice shoots and exerted several positive effects like the elongation of root and shoot length; similar reports for several plants like S. lycopersicum, Triticum aestivum, Glycine max, Z. mays, Brassica juncea, and Phaseolus mungo have been suggested (Khodakovskaya et al., 2009; Ghodake et al., 2010).

The accumulation of high organic matter in the soil is reported in the presence of FCNTs in comparison to CNTs treatment and control thus having higher organic carbon and total nitrogen. Therefore, the $\mathrm{pH}$ of soil turned is slightly acidic. However, treatments showed a slight change in $\mathrm{pH}$ parameter as compared to initial reading. These observations showed that the functionalized CNTs are more potent in the promotion and enhancement of the nutrient status of soil as compared to non-functionalized, multi-walled CNTs. The increase in carbon content in biomass is also observed after the treatment with CNTs. FCNTs showed the highest above and below-ground biomass then CNTs in comparison to control (Figure 5). Further, FCNTs showed the highest above ground biomass $\left(8.5 \mathrm{~g} \mathrm{~m}^{-2}\right)$ then CNTs 
$\left(6.4 \mathrm{~g} \mathrm{~m}^{-2}\right)$ and control. The increase in below ground biomass was also higher in FCNTs $\left(1.14 \mathrm{~g} \mathrm{~m}^{-2}\right)$ and CNTs $\left(0.87 \mathrm{~g} \mathrm{~m}^{-2}\right)$ compared to the control $\left(0.69 \mathrm{~g} \mathrm{~m}^{-2}\right)$. Greater below ground biomass may be due to the accumulation of high concentration of functioned CNTs observed around the base of the apical meristem of tomato roots. The apical meristem is located in the zone of cell division, where root elongation occurs. It was observed by Canas et al. (2008) studied the effect of functionalized and non-functionalized CNTs on different plants and observed that non-functionalized CNT inhibit root elongation in tomato whereas, functionalized CNTs increases the growth of below-ground part. It was also observed nanotube on the root surfaces of the tomato plant.

The growth parameters of tomato plants e.g. plant height, the number of leaves and flowers under the treatment of CNTs and FCNTs were evaluated and presented in Table 3. It is observed that plant height, the number of leaves and flowers increased with the advancement of crop age and reached its maximum at maturity where maximum plant height, leaves number and flowers recorded at 75-80 days after treatments (DAT). Khodakovskaya et al. (2013) studied on tomato plant and prove that multi-walled carbon nanotubes (CNTs) can affect plant phenotype and the composition of soil microbiota. Tomato plants grown in soil supplemented with CNTs produce two times more flowers and fruit compared to plants grown in control soil.
The height of the plant is slightly higher for FCNTs treated plant as compared to control and CNTs treated. Tomato plants grown in soil supplemented with FCNTs produced two times more leaves and also fruits with control plants. The increase of flower numbers for FCNTstreated plants resulted in an increase in the production of tomato fruits. Thus, the tomato plants treated with FCNTs solution produced two times more fruit per plant compared with control plants. The current study indicated that the treatment of FCNTs to the root of tomato plants is efficient for activation of the reproductive system of plants and lead to an increase in the production of fruits. Villagarcia et al. (2012) reported that the surface charge of CNTs affects the growth and expression of water channel protein in tomato plants. It is suggested that the level of aggregation, type and charge of the functional group in the surface of CNTs is critical for specific effects of CNTs on germination and growth of tomato seedlings.

Recently, Srivastava et al. (2018) and Shukla et al. (2019) reviewed and concluded that nanotechnology is one of the most promising solutions to overcome the shortcomings of traditional agricultural practices. At every stage of agriculture (seed storage, priming, germination, fertigation, post-harvest), nanotechnology promises to improve crop productivity and quality. The use of nanoparticles as seed priming agents to enhance seed germination and crop productivity is encouraging. Nano formulations positively influence seed germination, shoot to root ratio and overall growth.

Table 3 Vegetation analysis of tomato plant, at each 15 DAT (Days after treatment)

\begin{tabular}{|c|c|c|c|c|c|}
\hline & 15 DAT & $30 \mathrm{DAT}$ & $45 \mathrm{DAT}$ & $60 \mathrm{DAT}$ & 75 DAT \\
\hline \multicolumn{6}{|c|}{ Height $(\mathrm{cm}) /$ Plant } \\
\hline Control & $13.9 \pm 0.4$ & $15.9 \pm 0.5$ & $17.4 \pm 0.5$ & $19.9 \pm 0.5$ & $22.0 \pm 0.6$ \\
\hline CNTs & $16.3 \pm 0.3$ & $19.6 \pm 0.5$ & $22.0 \pm 0.3$ & $24.6 \pm 0.5$ & $26.6 \pm 0.6$ \\
\hline FCNTs & $19.5 \pm 1.0$ & $22.0 \pm 0.6$ & $26.2 \pm 0.6$ & $28.3 \pm 0.3$ & $30.3 \pm 0.3$ \\
\hline$L S D$ & 2.38 & 1.80 & 1.94 & 1.40 & 1.74 \\
\hline \multicolumn{6}{|c|}{ Number of leaves/Plant } \\
\hline Control & $2 \pm 0.3$ & $5 \pm 0.3$ & $6 \pm 0.4$ & $7 \pm 1.0$ & $9 \pm 0.3$ \\
\hline CNTs & $3 \pm 0.3$ & $6 \pm 0.5$ & $7 \pm 0.6$ & $11 \pm 0.6$ & $14 \pm 0.5$ \\
\hline FCNTs & $6 \pm 0.4$ & $9 \pm 0.5$ & $11 \pm 1.0$ & $14 \pm 0.6$ & $16 \pm 0.8$ \\
\hline$L S D$ & 1.15 & 1.76 & 2.49 & 1.76 & 1.26 \\
\hline \multicolumn{6}{|c|}{ Number of Flowers/Plant } \\
\hline Control & - & - & - & - & $8 \pm 0.6$ \\
\hline CNTs & - & - & - & budding started & $12 \pm 0.5$ \\
\hline FCNTs & - & - & - & budding started & $15 \pm 0.8$ \\
\hline$L S D$ & - & - & - & - & 2.40 \\
\hline
\end{tabular}

Treatments were CNTs (Multi-walled carbon nanotubes) and FCNTs (functionalized multi-walled carbon nanotubes), Values are replicate (nine)mean $\pm S E$ and are significant at $0.05(p<0.05)$.

Journal of Experimental Biology and Agricultural Sciences http://www.jebas.org 
In the present investigation, the significant increase in tomato growth was achieved when tomato seedlings were exposed to welldispersed carboxylic group functionalized CNTs (COOH-CNTs). The COOH-CNTs have a high negative surface charge it also reduces the CNTs aggregation. It is assumed that the CNTs have $\mathrm{Ca}$ and $\mathrm{Fe}$ nutrients uptake efficiency and these nano tubes interact with the roots of the tomato plant and promote plant growth. The mechanism of observed effects of FCNTs on plant reproductive systems will require future detailed investigation.

\section{Conclusion}

In the present study, we have functionalized the CNTs with the carboxylic group by chemical oxidation method. The diameter of as synthesized CNTs was found to be $\sim 30-50 \mathrm{~nm}$. The FTIR analysis confirmed the presence of the $\mathrm{COOH}$ group on the surface of CNTs. The effects of CNTs and FCNTs on the growth of tomato plants were investigated. It was observed that the FCNTs mixed in soil not only improve soil basic characteristics but also enhance height, leaves, flowers and fruit of tomato plant as compared to plants grown with CNTs and control soil. A detailed study about the mechanism is still a point of investigation.

\section{Abbreviations}

CNTs, carbon nanotubes; FCNTs, functionalized carbon nanotubes; SEM, scanning microscopy; TEM, transmission electron microscopy; FTIR, Fourier transform infrared.

\section{Acknowledgements}

We thank the Head and Course Co-ordinator of Environmental Science (Environmental Technology), RGSC, Institute of Environment and Sustainable Development and Prof. O. N. Srivastava, Coordinator Nanoscience Centre, Department of Physics, Banaras Hindu University for providing laboratory and field facilities. We are also thankful to M. Sc. students for extending their heartfelt cooperation and support during experimentation.

\section{Conflict of interest}

The authors declare that they have no conflict of interest

\section{References}

Abbas SS, Haneef M, Lohani M, Tabassum H, Khan AF (2016) Nanomaterials used as a plants growth enhancer: an update. International Journal of Pharmaceutical Sciences Review and Research 5(7):17-23.

Awasthi K, Awasthi R (2019) Carbon Nanomaterials for Crop Management, In: Srivastava R (Ed.) Sustainable Practices for
Natural Resource Management through Biological Tools. Bharti Publication Pp. 1-12.

Canas JE, Long M, Nations S, Vadan R, Dai L, Luo M, Ambikapathi R, Lee EH, Olszyk D (2008) Effects of functionalized and nonfunctionalized single-walled carbon nanotubes on root elongation of selected crop. Environmental Toxicology and Chemistry 27(9): 1922-1931.

Chhipa H (2019) Applications of nanotechnology in agriculture. Methods in Microbiology 46: 115-142.

Ghodake G, Seo YD, Park D, Lee DS (2010) Phytotoxicity of carbon nanotubes assessed by Brassica juncea and Phaseolus mungo. Journal of Nanoelectronics and Optoelectronics 5(2):157160 .

Husen A, Siddiqi KS (2014) Carbon and fullerene nanomaterials in plant System. Journal of Nanobiotechnology 12:16.

Jackson ML (1958) Soil chemical analysis. Prentice-Hall, Englewood, Cliffs, New Jersey, pp. 485

Janas D, Stando G (2017) Unexpectedly strong hydrophilic character of free-standing thin films from carbon nanotubes. Science Report 7: 12274.

Kharisov BI, Kharissova OV, Gutierrez HL, Mendez UO (2009) Recent advances on the soluble carbon nanotubes. Industrial and Engineering Chemistry Research 48(2):572-590.

Khodakovaskaya MV, Kim BS, Kim JN, Mahmood M, Dervishi E, Mustafa T, Cernigla CE (2013) Carbon nanotubes as plant growth regulators: Effects on tomato growth, reproductive system and soil microbial community. Small 9(1): 115-123.

Khodakovskaya M, Dervishi E, Mahmood M, Xu Y, Li Z, Watanabe F, Biris AS (2009) Carbon nanotubes are able to penetrate plant seed coat and dramatically affect seed germination and plant growth. ACS Nano 3(10): 3221-3227.

Khot LR, Sankaran S, Maja JM, Ehsani R, Schuster EW (2012) Applications of nanomaterials in agricultural production and crop protection: A review. Crop Protection 35: 64-70.

Lahiani MH, Dervishi E, Chen J, Nima Z, Gaume A, Biris AS, Khodakovskaya MV (2013) Impact of carbon nanotube exposure to seeds of valuable crops. ACS Applied Materials and Interfaces 5: 7965-7973.

Manjunatha SB, Biradar DP, Aladakatti YR (2016) Nanotechnology and its applications in agriculture: A review. Journal of Farm Sciences 29(1): 1-13. 
Mohamed AM, Ayat FH, Mousa AA, Abd-Elsalam KA (2018) Nano-carbon: Plant Growth Promotion and Protection, In: AbdElsalam KA, Prasad R (Eds.) Nanobiotechnology Applications in Plant Protection, Nanotechnology in the Life Sciences. Springer, Berlin, Pp155-188.

Mondal A, Basu R, Das S, Nandy P (2011) Beneficial role of carbon nanotubes on mustard plant growth: an agricultural prospect. Journal of Nanoparticles Research 13: 4519-4528.

Mukherjee A, Majumdar S, Servin AD, Pagano L, Dhankher OP, White JC (2016) Carbon Nanomaterials in Agriculture: A Critical Review. Frontiers in Plant Science 172 (sp.7): 1-16.

Nalwade AR, Neharkar SB (2013) Carbon nanotubes enhance the growth and yield of hybrid Bt cotton Var. ACH-177-2. International Journal of Advanced Scientific and Technical Research 3:840-846.

Parisi C, Vigani M, Rodríguez-Cerezo E (2015) Agricultural Nanotechnologies: What are the current possibilities? Nano Today 10: $124-127$.

Patel A, Tiwari S, Parihar P, Singh R, Prasad SM (2019) Carbon nanotubes as plant growth regulators: Impacts on growth, reproductive system and soil microbial community In: Tripathi DK, Ahmad P, Sharma S, Chauhan DK, Dubey NK (Eds.) Nanomaterials in plants, algae and microorganisms: Concepts and controversies. Academic press, 2: 23-42.

Piper CS (1966) Soil and plant analysis. Hans publishers, Bombey, Pp. 366.

Prasad R, Kumar V, Prasad KS (2014) Nanotechnology in sustainable agriculture: Present concerns and future aspects African Journal of Biotechnology 13(6): 705-713.

Shukla P, Chaurasia P, Younis K, Qadri OS, Faridi SA, Srivastava G (2019) Nanotechnology in sustainable agriculture: Studies from seed priming to post-harvest management. Nanotechnology for Environmental Engineering 4: 11.

Srinivasan C, Saraswathi R (2010) Nano-agriculture-carbon nanotubes enhance tomato seed germination and plant growth. Current Science 99:273-275.
Srivastava A, Rao DP (2014) Enhancement of seed germination and plant growth of wheat, maize, peanut and garlic using multiwalled carbon nanotubes. European Chemical Bulletin 3(5): 502-504.

Srivastava A, Srivastava ON, Talapatra S, Vajtai, Ajayan PM (2004) Carbon nanotube filters. Nature Materials 3: 610-4.

Srivastava R (2019) Book review of emerging trends of nanotechnology in environment and sustainability. Australasian Journal of Environment and Management 26(2): 191-192.

Srivastava R, Awasthi K, Tripathi D (2018) Nanotechnology towards sustainable agriculture.International Journal of Scientific Research in Physics and Applied Sciences 6: 155-158.

Srivastava R, Mohapatra M, Latare A (2020) Impact of land use changes on soil quality and species diversity in the Vindhyan dry tropical region of India. Journal of Tropical Ecology 36(1):72-79.

Stobinski L, Lesiak B, Kover L, Toth J, Biniak S, Ykowski G, Judek J (2010) Multiwall carbon nanotubes purification and oxidation by nitric acid studied by the FTIR and electron spectroscopy methods. Journal of Alloys and Compounds 501:77-84

Tripathi S, Sonkar SK, Sarkar S (2011) Growth stimulation of gram (Cicerarietinum) plant by water soluble carbon nanotubes. Nanoscale 3: 1176-1181.

Verma SK, Das AK, Gantait S, Kumar V, Gurel E (2019) Applications of carbon nanomaterials in the plant system: A perspective view on the pros and cons. Science of the Total Environment 667: 485-499

Villagarcia H, Dervishi E, de Silva K, Biris AS, Khodakovskaya MV (2012) Surface chemistry of carbon nanotubes impacts the growth and expression of water channel protein in tomato plants. Small 8(15):2328-2334.

Walkley A (1947) A critical examination of a rapid method for determination of organic carbon in soils - effect of variations in digestion conditions and of inorganic soil constituents. Soil Science 63: 251-257.

Wang X, Han H, Liu X, Gu X, Chen K, Lu D (2012) Multi-walled carbon nanotubes can enhance root elongation of wheat (Triticum aestivum) plants. Journal of Nanoparticle Research 14: 841-850. 